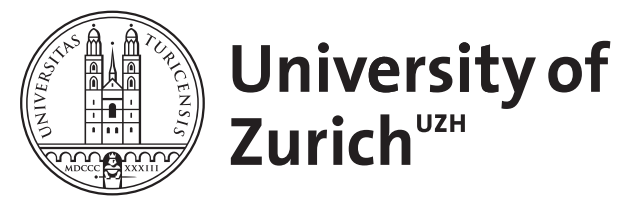

\title{
Synthesis and Structure of a 1,2,5,7-Benzothiatriazonine
}

\author{
Schläpfer-Dähler, Marlise ; Prewo, Roland ; Bieri, Jost H ; Heimgartner, Heinz
}

\begin{abstract}
Dimethylamino-2,2-dimethyl-2H-azirine (1) and 4-phenyl-3,4-dihydro-2H-1,2,4-benzothiadiazin3-on-1,1-dioxide (6) react already below room temperature to give a nine-membered heterocyclic product, namely 3-dimethylamino-4,4-dimethyl-7-phenyl-4,5,6,7-tetrahydro-1,2,5,7-benzothiatriazonin-6-on-1,1-dioxide (7, Scheme 2) in a quantitative yield. The structure of this new heterocycle has been confirmed by X-ray crystallographic analysis (Fig. 1 and 2). In Scheme 2 a reaction mechanism for the formation of 1 is discussed, the zwitterion b being the key intermediate.
\end{abstract}

Posted at the Zurich Open Repository and Archive, University of Zurich ZORA URL: https://doi.org/10.5167/uzh-96883

Journal Article

Published Version

Originally published at:

Schläpfer-Dähler, Marlise; Prewo, Roland; Bieri, Jost H; Heimgartner, Heinz (1984). Synthesis and Structure of a 1,2,5,7-Benzothiatriazonine. Heterocycles, 22:1667-1672. 
SYNTHESIS AND STRUCTURE OF A $1,2,5,7$-BENZOTHIATRIAZONINE

Marlise Schläpfer-Dăhler a), Roland Prewo, Jost H. Bieri, and Heinz Heimgartner *

Organ1sch-chemisches Institut der Universităt Zürich, Winterthurerstrasse 190, CH-8057 zürich, Switzerland

Abstract - 3-Dimethylamino-2,2-dimethyl-2H-azirine (1) and 4pheny 1-3,4-dihydro-2H-1,2,4-benzothiadlazin-3-on-1,1-dioxide (ㅁ) react already below room temperature to give a nine-membered heterocyclic product, namely 3-dimethylamino-4,4-dimethy1-7-phenyl-4,5, 6,7-tetrahydro-1,2,5,7-benzothiatriazonin-6-on-1,1-dioxide 1 , Scheme 2) in a quantitative yleld. The structure of this new heterocycle has been confirmed by $\mathrm{x}$-ray crystallographic analysis (Fig. 1 and 2). In Scheme 2 a reaction mechanism for the formation of $\underline{7}$ is discussed, the zwitterion $\underline{b}$ being the key intermediate.

Several years ago, we have reported that 3-dimethylamino-2,2-dimethy1-2H-azirine (1) reacts with saccharine (2) to give the 1,2,5-benzothiadtazocine 3 by a ring expansion reaction 1 (Scheme 1). Similar reactions have been observed with phthalimide and with malonimides, yielding 1,4-benzodiazoctne $\underline{4}^{1}$ and 1,4-diazepines of type $\underline{5}^{2}$, respectively (Scheme 1 ).

Following this principle, we have made strong efforts to realize ring expansion reactions to nine-membered nitrogen heterocycles, starting with aminoazirine 1 and six-membered NH-acidic heterocycles. But all these reactions led to other products than medium sized rings ${ }^{3-6}$ (cf. also ${ }^{7}$ ). We will now report on the first successful ring expansion reaction of this type, leading to a 1,2,5,7-thiatriazonine derivative. This ring system $1 \mathrm{~s}$, as far as we know, not reported in literature.

a) Part of the Ph.D. thesis of M.S.-D. 
Scheme 1

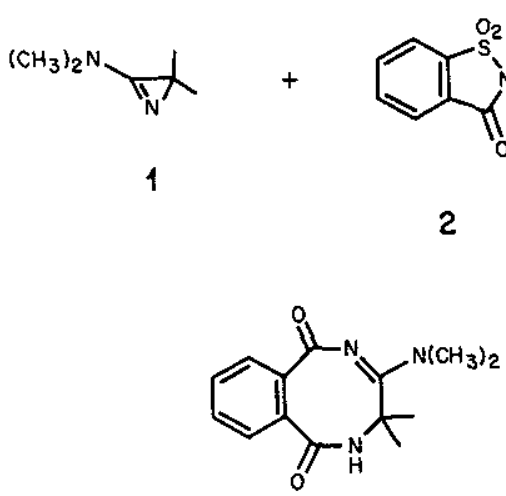

4

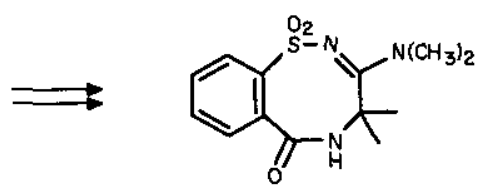

3<smiles>[R]C1([R2])C(=O)N=C(N(C)C)C(C)(C)NC1=O</smiles>

5

The six-membered starting material 4-phenyl-3,4-dihydro-2H-1,2,4-benzothiadiazin3-on-1,1-dioxide ( 6 ), has been synthesized in analogy to the reported method ${ }^{8}$, starting with diphenylamine and chlorosulfonyl isocyanate. In chloroform, the heterocyclic compound $\underline{6}$ reacts with aminoazirine 1 already below room temperature. Treatment of a suspension of $274 \mathrm{mg}(1 \mathrm{mmol})$ of 6 in $5 \mathrm{ml}$ of chloroform with $112 \mathrm{mg}$ (1 mol) of 1 at about $-15^{\circ} \mathrm{C}$ and slowly warming up to room temperature yields a clear solution, and after evaporation of the solvent, an amorphous solid remains. Recrystallization from chloroform/ether yields $385 \mathrm{mg}$ (99.5\%) of 3-dimethylamino4,4-dime thy 1-7-phenyl-4, 5, 6,7-tetrahydro-1,2,5,7-benzothiatriazonin-6-on-1,1-dioxide (7. Scheme 2) as colourless crystals, mp $164-165^{\circ} \mathrm{C}$ (decomp.).

Scheme 2<smiles>C=CC(=O)N1C(=O)N[Sb](=O)(c2ccccc2)c2ccccc21</smiles><smiles></smiles>

$7 \mathbf{a}$

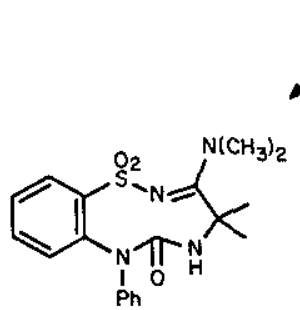

7 
Elemental analysis ${ }^{9}$ and spectroscopic data of $\underline{7}$ suggest the structure of a (1:1)adduct of azirine 1 and the heterocycle $\underline{6}$. In the ir (KBr), absorption bands for $\mathrm{NH}\left(3420\right.$ and $\left.3290 \mathrm{~cm}^{-1}\right)$, for an amide-carbonyl as well as an amidine group (1692, 1587,1565 and $\left.1543 \mathrm{~cm}^{-1}\right)$, and for the $\mathrm{SO}_{2}$-function (1399 and $\left.1144 \mathrm{~cm}^{-1}\right)$ appear. The ${ }^{1} \mathrm{H}-\mathrm{nmr}$ spectrum $\left(\mathrm{CDCl}_{3}\right)$ shows multiplets for aromatic protons at $8.3-8.1$ (1H) and $7.5-6.9(8 \mathrm{H}) \mathrm{ppm}$, a singlet at $4.87 \mathrm{ppm}$ for $\mathrm{NH}$, a sharp singlet at $3.43 \mathrm{ppm}$ for the $\left(\mathrm{CH}_{3}\right)_{2} \mathrm{~N}-$ group and two broad signals at 2.07 and $1.43 \mathrm{ppm}$ for the geminal dimethyl group. In the ${ }^{13} \mathrm{C}$-nmr spectrum $\left(\mathrm{CDCl}_{3}\right)$, besides the signals of the aromatic c-atoms, two absorptions which can be correlated with an amidine-c-atom and an urea-carbonyl group, appear at low fleld (172.1 and 156.5 ppm). A sharp signal at 61.9 ppm corresponds to $c(4)$ of $\underline{Z}$ and a broad signal at $43.7 \mathrm{ppm}$ to the dimethylamino group. The c-atoms of the geminal dimethyl group appear again as broad signals at 30.2 and $26.7 \mathrm{ppm}$. These broad methyl absorptions in the $1_{\mathrm{H}-}$ as well as in the ${ }^{13} \mathrm{C}-\mathrm{nm}$ can be explained by a slow conformational change of the nine-membered ring system.

The mentioned spectroscopic data are not unambiguous; they are in accord with structure 7 as well as 7 a (Scheme 2). Therefore, we have decided to proof the structure of the (1:1)-adduct by $x$-ray crystallography. Colourless single crystal of $\underline{7}$ has been obtalned from chloroform/acetonitrile/ether. They belong to the monoclinic space group $C c$ with $a=16.724(1), b=9.775(1), c=12.125(1) \AA, \beta=109.82(1)^{\circ}$, and $V=1862.8 \mathrm{~A}^{3}$. The intensities of 3469 independent reflexions were measured at ca. $-140^{\circ} \mathrm{C}$ with monochromatized $\mathrm{MoK}_{\alpha}$ radiation ( $\omega$-scan mode) on a N1colet $\mathrm{R} 3$ fourcircle diffractometer within $2 \theta<65^{\circ}$. The structure was solved by direct methods using sHELXTL 10 . In the blocked cascade refinement (ca. 100 variables/block) the H-atoms were varied with isotropic temperature factors after their location in a difference electron density map while the other atoms were refined anisotropically. An empirical extinction coefficient was also included. The refinement converged at an $R$-value of 0.027 using all reflexions.

The molecular structure of $\underline{7}$ is given in Fig. 1, bond lengths, bond angles and torsion angles of the puckered nine-membered ring are shown in Fig. 211 . 


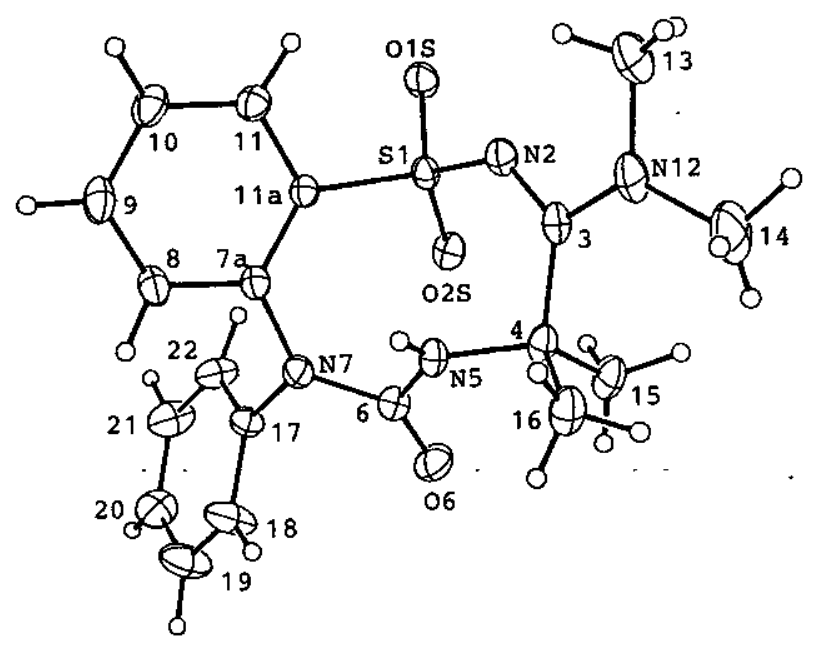

Fig. 1. Molecular structure of the 4,5,6,7-tetrahydro-1,2,5,7-benzothiatriazonin6-on-1,1-dioxide $\underline{7}$.

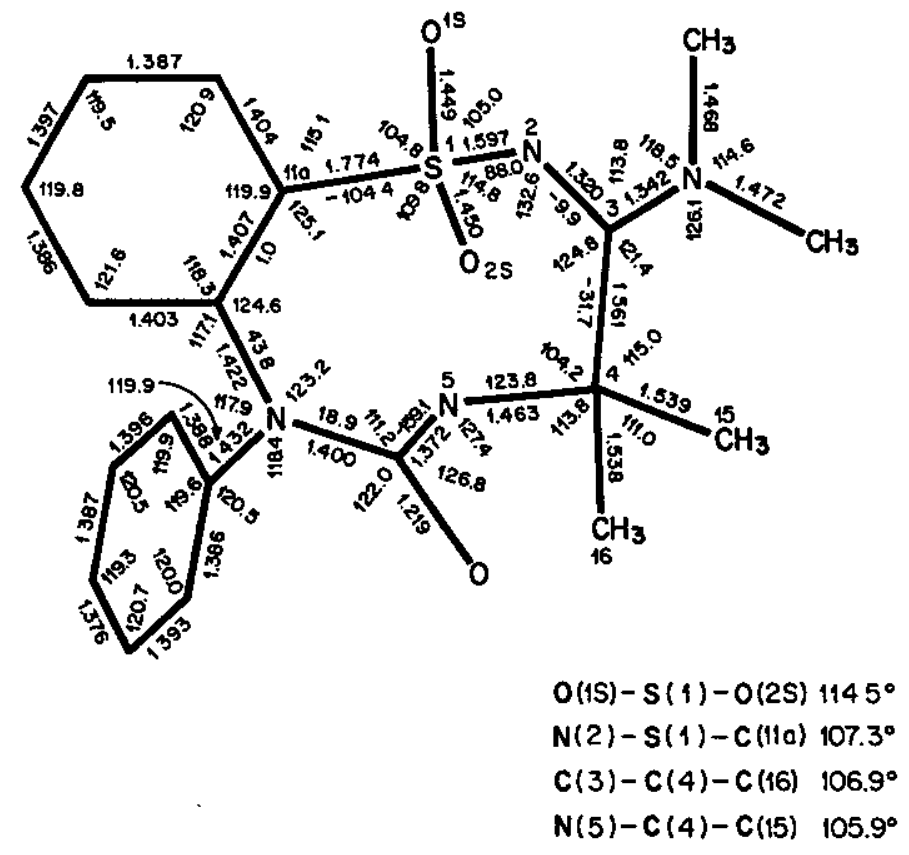

Fig. 2. Bond lengths in $\&$ (e.s.d.s $0.001-0.003 \AA$ ), bond angles and intraannular 9-ring torsion angles in degrees (e.s.d.s 0.1-0.2 degree) of compound $\underline{7}$. 
A reasonable reaction mechanism for the formation of 7 is given in Scheme 2 . The aziridine intermediate $\underline{a}$, generated via protonation of azirine 1 by the NH-acidic heterocycle $\underline{6}$ and nucleophilic attack of the anion to the amidinium $c$-atom, undergoes a rearrangement to give the zwitterion $\underline{b}$ (cf. ${ }^{1-7}$ ). In this step, the cleavage of the original $\mathrm{C}-\mathrm{N}$ double bond of azirine 1 occurs. Breaking of the central $\mathrm{C}-\mathrm{N}$ bond of $\underline{b}$ leads then to the ring expanded heterocycle $\underline{7}$.

It seems that the aminoazirine 1 and NH-acidic heterocycles of type $\underline{8}$ usually react to give the nonisolated zwitterionic intermediate $\underline{c}$ as the primary product (Scheme 3). Until now we have observed several different reactions of $c$ a) Ring enlargement via cleavage of the central $\mathrm{C}-\mathrm{N}$ bond leads to the $(n+3)$-membered heterocycle of type $\underline{9}^{1,2}$. b) With $\mathrm{x}=$ CONH a profound rearrangement including a decarboxylation takes place, leading to 5-dimethylamino-4,4-dimethyl-4H-1midazoles of type $\underline{10} 3,5,12$. c) The zwitterion $\subseteq$ from 1 and cyclic hydrazides $(\mathrm{X}=$ NHCO) loses water to yield the new zwitterion 11 as a stable compound 13 . d) In some cases, $\mathrm{c}$ can be hydrolized to give imidazolinones of type $\underline{12}^{14,15}$. We were able to show that the reaction sequences a) and b) are general, whereas c) and d) as well as a few other reactions of 1 with $\mathrm{NH}$-acidic heterocycles $6,12,16$ are of limited scope.

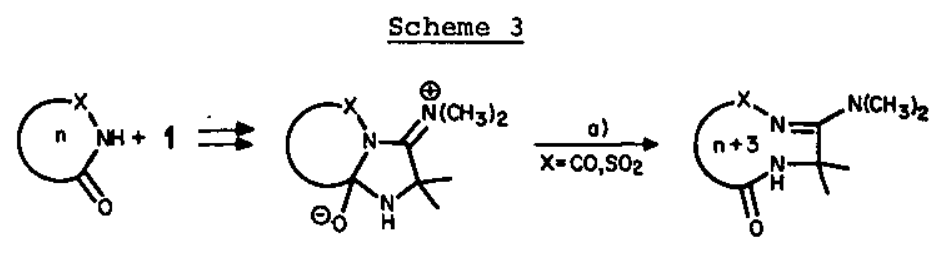

8

c

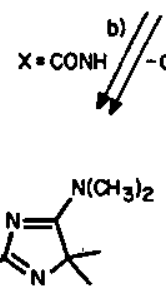

10<smiles>O=[N+]([O-])[O-]</smiles><smiles>CN1C(=O)CCCC2=NC(C)(C)N(C)C21</smiles>

11
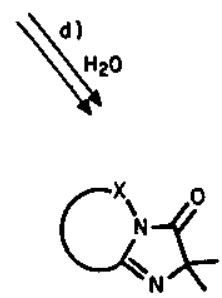

12

ACKNOWLEDGEMENTS The support of this work by the Swiss National science Foundation and by F. Hoffmann-La Roche Co. AG, Basel, is gratefully acknowledged. 
1 S. Chaloupka, P. Vittorelli, H. Heimgartner, H. Schmid, H. Link, K. Bernauer, and W.E. Oberhänsli, Helv. Chim. Acta, 60, 2476 (1977).

2 B. Scholl, J.H. Bieri, and H. Heimgartner, Helv. Chim. Acta, 61, 3050 (1978).

3 G. Mukherjee-Mïller, S. Chaloupka, H. Heimgartner, H. Schmid, H. Link, K. Bernaver, P. Schönholzer, and J.J. Daly, Helv. Chim. Acta, 62, 768 (1979).

4 H. Link, K. Bernauer, J.J. Daly, S. Chaloupka, and H. He1mgartner, Helv. Chim. Acta, $64,49(1981)$

5 M. Dähler, R. Prewo, J.H. Bieri, and H. Heimgartner, He1v. Chim. Acta, 65, $2302(1982)$

6 B.P. Chandrasekhar, J.H. Bieri, H. Heimgartner, G. Germain, and J.-P. Declercg, Heterocycles, 19, 2079 (1982).

7 H. Heimgartner, J. Israel Chem., 21, 151 (1981); cf. also H. Heimgartner, Wiss. Z. Karl-Marx-Univ. Leipzig, Math.-Naturwiss. R. , 32; 365 (1983).

8 Y. Girara, J.G. Atkinson, and J. Rokach, J. Chem. Soc. Perkin I, 1979, 1043. $9 \mathrm{C}_{19} \mathrm{H}_{22} \mathrm{~N}_{4} \mathrm{O}_{3} \mathrm{~S}(386.48)$; calculated: C $59.05, \mathrm{H} 5.74, \mathrm{~N} 14.50, \mathrm{~S} 8.308$; found: C $58.84, \mathrm{H} 5.85, \mathrm{~N} 14.25, \mathrm{~S} 8.068$.

10 G.M. Sheldrick, SHELXTL, Revision 3.0 (1981).

11 The coordinates of the atoms have been sent to the Cambridge Crystallographic Data Centre. Further information on the structure determination can be obtained from $\mathrm{J}, \mathrm{H}, \mathrm{B}$.

12 M. Schläpfer-Dähler, planned thesis, University of zürich.

13 H. Link, K. Bernauer, s. Chaloupka, H. Heimgartner, and H. Schmid, Helv. Chim. Acta, $61,2116(1978)$

14 S. Chaloupka, J.H. Bieri, and H. Heimgartner, Helv, Chim. Acta, 63, 1797 (1980).

15 F. Stierli, planned thesis, University of Zürich.

16 M. Dählex, R. Prewo, J.H. Bieri, and H. Heingartner, Helv. Chim. Acta, 66, $1456(1983)$ 